\title{
A IRONIA COMO EXPEDIENTE RETÓRICO EM CONTOS BRASILEIROS
}

MIRANDA, Maria Geralda de CERQUEIRA, Alex Ribeiro

\section{ALGUMAS CONSIDERAÇÕES SOBRE A RETÓRICA:}

A retórica, ou arte de convencer e persuadir surgiu em Atenas, na Grécia antiga, por volta de 427 a.C., quando os atenienses estavam vivendo a primeira experiência de democracia de que se tem notícia na história. Em razão disso, era muito importante que os cidadãos conseguissem dominar a arte de bem falar e de argumentar, nas assembleias populares e nos tribunais", (ABREU, 2005: 28).

A argumentação, importante não só nos primórdios do que hoje conhecemos como democracia, vem servindo também como instrumento de práticas libertadoras e solidificadoras das relações humanas. Como diz Perelman (1996: 10), "o objetivo de toda argumentação é provocar ou aumentar a adesão dos espíritos às teses que se apresentam a seu assentimento: uma argumentação eficaz é a que consegue aumentar essa intensidade de adesão.

A leitura retórica não objetiva dizer que o texto tem razão ou deixa de ter. Nem por isso é neutra, pois não hesita em fazer juízos de valor, em mostrar que tal argumento é forte ou fraco, que tal conclusão é legítima ou errônea. "Critica e pondera, sem se abster de admirar, tendo como postulado que o texto, tanto em sua força quanto em suas fraquezas, pode ensinar alguma coisa. A leitura retórica é um diálogo", (REBOUL, 2004:132).

O ponto de vista para o qual o orador/autor busca a adesão do auditório pode ser dito clara e diretamente ou, frequentemente, utilizar-se de técnicas retóricas para atingir objetivos e persuadir. Para Reboul (2004: 141), o discurso tende a persuadir de algo, mas esse algo pode ser múltiplo. $O$ texto muitas vezes tem um objetivo 
imediato e outro distante. O distante quase sempre é o mais importante, posto que é apenas sugerido, pressuposto ou subentendido na "capilaridade" do discurso.

Em textos irônicos, como os que são objetos deste estudo, o objetivo real pode ser absolutamente oposto ao objetivo declarado. Uma visão de mundo pode ser defendida, fundamentada, analisada, dimensionada, avaliada, a partir da ironia e das construções cômicas. Alguns artistas da palavra manejam com mestria as técnicas e a arte de fazer o outro rir, desenvolvendo-as e aperfeiçoando-as através do tempo, acompanhando as conquistas sociais e políticas da sociedade.

O riso tem um profundo valor de concepção do mundo, é uma das formas capitais pelos quais se exprime a verdade sobre o mundo na sua totalidade (...) somente o riso, com efeito, pode ter acesso a certos aspectos extremamente importantes do mundo. (BAKHTIN, 1993:.57).

Segundo Aristóteles, a criança começa a rir no quadragésimo dia depois do nascimento, momento em que se torna pela primeira vez um ser humano. Já Plínio afirmava que um único homem no mundo, Zoroastro, começara a rir assim que nascera, o que permitia augurar a respeito da sua sabedoria divina. (BAKHTIN, 1993: 59).

Dado o objeto de análise deste estudo configurar-se como contos brasileiros construídos sob o viés da ironia, é oportuno observar os efeitos de sentido que a ironia produz nos textos analisados. Mikhail Bakhtin, que investigou o riso na obra de François Rabelais, aponta importantes facetas das manifestações da cultura popular, que contribuíram para a visão do escritor francês, como o riso proporcionado pelo carnaval e por obras cômicas verbais, escritas em latim ou língua "vulgar" e também pelo vocabulário familiar e grosseiro, que continha insultos, juramentos e fanfarronices populares.

Entre as numerosas investigações científicas consagradas aos ritos, mitos e às obras populares 
líricas e épicas, o riso ocupa apenas um lugar modesto. O mundo infinito das formas $e$ manifestações do riso opunha-se à cultura oficial, ao tom sério, religioso e feudal da época... A literatura cômica chegou à sua apoteose durante o apogeu do Renascimento, com o Elogio da loucura, de Erasmo. (BAKHTIN, 1993:3).

Contar histórias é algo muito antigo, sendo praticamente impossível precisar desde quando existe tal prática. Os contos mágicos egípcios datam de 4.0000 a.C, mas sabe-se que a arte de contar passa por fases e evoluções. As histórias sempre reuniram pessoas que contam e que ouvem. Em sociedades tradicionais (ágrafas ou não) sacerdotes se reuniam e ainda se reúnem com seus discípulos para transmissão dos mitos e ritos da tribo; em nossos tempos, em volta da mesa, à hora das refeições, pessoas trazem notícias, trocam ideias e contam casos. (GOTLIB, 2000:.5).

As histórias, do modo com a tradição as utilizavam, para além do exercício lúdico, sempre foram aplicadas para fazer transmitir uma determinada ideia, a partir da qual se mantinha a própria tradição, porque deixavam uma mensagem. Persuadia os ouvintes de alguma coisa e para alguma coisa. Segundo Perelman (1996:16), "quando somos convencidos, somos vencidos apenas por nós mesmos, pelas nossas idéias. Quando somos persuadidos, sempre o somos por outrem". As histórias escritas, modernas ou não, não deixaram de possuir esta função precípua de veicular uma mensagem, um posicionamento. Ainda quando o autor, ou o narrador, diz não tratarse de posicionamento nenhum.

Aristóteles trabalha com três conceitos fundamentais a qualquer discurso: "pathos", "ethos" e "logus". Simplificando a teorização do filósofo, o "ethos" tem a ver com a formação da credibilidade do orador, junto à audiência. O "pathos" é designado por Aristóteles como a forma de trabalhar as emoções do auditório, os apelos e ferramentas das quais o orador se servirá para atingir o emocional 
dos seus ouvintes ou leitores. O "logus" se relaciona ao convencimento do auditório, neste caso o leitor, através de técnicas que visem tratar do raciocínio lógico, da razão, de provas irrefutáveis.

Para a retórica, o discurso pode ser oral ou escrito, é com ele, ou a partir dele, que o orador, ou emissor, deseja convencer o auditório, ou audiência. É em função da tese, ou ponto de vista, que o orador procura estruturar o seu discurso, ordenar seus argumentos e elaborar suas estratégias de convencimento.

As teses, ou as idéias que se pretende que o auditório compartilhe com o orador, precisam ser apresentadas em uma linguagem clara e objetiva, a fim de facilitar a empatia e consequente assimilação das propostas. É condição fundamental ao exercício bem sucedido da condição de orador, ou contista, no caso deste trabalho, o conhecimento prévio do auditório e o manejo das técnicas retóricas, ou literárias, neste caso, para a ação dirigida de forma agradável, sem as quais se torna impossível a conquista da audiência, ou dos leitores dos contos.

Orador, auditório: é impossível que um se dirija ao outro se não houver entre ambos um acordo prévio. De fato, não há diálogo, nem mesmo argumentação, sem um entendimento mínimo entre os interlocutores, entendimento referente tanto aos fatos quanto aos valores. Pode-se até dizer, sem paradoxo, que o desacordo só é possível no âmbito de um acordo comum. Nas questões em que não haja nenhum acordo inicial, pode haver violência ou ignorância recíproca, não controvérsia. (REBOUL, 2004:142).

Cabe ao orador conquistar o seu auditório, provando a validade de sua proposta. Também pode, através do seu discurso, que acaba sendo também a sua arte, fornecer e extrair dados que identifiquem um auditório ou um perfil de auditório de seu tempo, numa relação de contribuição com outras áreas do saber humano. Seu discurso pode elevá-lo a uma condição de historiador de sua época, 
registrando aspectos políticos, sociais e morais que prevalecem sobre determinado tipo de auditório.

Os contos selecionados foram produzidos em épocas diferentes. A escolha, conforme já se disse, foi pelo fato de todos eles se valerem da ironia como expediente retórico. Arthur Azevedo e João do Rio utilizam a literatura e os contos de humor para estabelecerem convencimento e persuasão ao seu auditório, seus leitores.

\section{DESVENDANDO OS ARGUMENTOS DOS CONTOS:}

O conto "De cima para baixo", de Artur Azevedo, escrito em 1870, narra uma história vivenciada no Segundo reinado, época do imperador Pedro II. Esta década dá início a questões que levarão a profundas mudanças no Brasil. Inicia-se um período de isolamento político do Império, até que, no final da década de 1870, diversas forças políticas passaram a exigir, cada vez mais, o fim do escravagismo. Nasce, nesta época, a ideia da formação de um partido republicano, que se desembocará no fim do Império brasileiro e na proclamação da República, em 1889.

Resumidamente, a história é a seguinte: um decreto de nomeação é expedido sem constar o nome do beneficiado e chega à mesa do imperador. Quem é o culpado? Tamanho erro burocrático desencadeia uma série de reações entre chefes e subordinados nas repartições públicas brasileiras, revelando detalhes da mecânica das relações de poder da época.

Vê-se que o jovem país, Brasil, já sofria com a burocratização da máquina do Estado. O contista revela a mesquinhez do homem que se acha superior ao seu chefiado, convidando, com recursos da retórica e da literatura, a pensar no ridículo que se estabelece quando no lugar da competência entram a vaidade e a lisonja.

A construção de sua credibilidade de autor (o seu "ethos") perante o leitor começa a se constituir a partir da escolha de um 
narrador onipresente, cuja credibilidade inequívoca baseia-se no fato de ele ser sabedor das ações e sentimentos das personagens, dosando o desvendar das ações e dos sentimentos ao longo do conto, de forma que o leitor/auditório vá tomando ciência e, consequentemente, descobrindo a trama e suas construções discursivas. As ações das personagens, que se alternam nas funções de chefes e subordinados, portanto em contato com os superiores e inferiores na hierarquização do trabalho, possibilitam o desvendar das múltiplas relações entre eles.

O modo pelo qual o autor lida com as emoções do auditório/leitor (o "pathos") leva em conta a mescla de sentimentos e emoções como a agressividade do superior frente ao seu inferior hierárquico e a contrapartida da sua subserviência quando trata com um superior na hierarquia de trabalho. O convencimento do leitor para uma dada verdade, ou realidade, através do raciocínio lógico ("logus") encontram eco na estrutura burocrática que rege o trabalho público e, em especial, o documento de nomeação, aproveitando-se de uma memória do leitor no que se refere às relações lógicas e costumeiras auferidas às relações de trabalho.

Neste conto, os gêneros discursivos parecem mesclar-se, como em grande parte das obras literárias, a partir da idade contemporânea. A retórica clássica considerava que os discursos estavam ligados a três situações fundamentais: quando o autor defende ou ataca alguém, tentando provar a sua inocência ou culpa, o usado é o gênero judiciário. O gênero epidíctico exalta os méritos ou critica os defeitos de algo ou alguém. O gênero deliberativo, em que o orador aconselha ou desaconselha sobre uma coisa futura tem o discurso centrado nas categorias do útil e do nocivo, pretendendo que o auditório tome uma decisão.

Alguns argumentos, ou lugares do discurso, precisam convencer e muitas vezes levar a agir. Os lugares firmam a hierarquização de valores, reforçando a adesão à tese principal. Na 
utilização dos argumentos, o autor utiliza-se do argumento de autoridade, aquele em que é citado alguém de reconhecida importância e, portanto, inquestionável em seus saberes e em suas ações. Veja um exemplo do início do conto: "- Estou furioso! Exclamou o conselheiro. - Por sua causa passei por uma vergonha diante de Sua Majestade o Imperador!" (AZEVEDO, 2001: 293).

Algumas técnicas conhecidas desde a Antigüidade recebiam o nome de lugares da argumentação. São premissas de ordem geral utilizadas para reforçar a adesão a determinados valores. O nome lugares era utilizado pelos gregos, para denominar locais virtuais facilmente acessíveis, onde o orador pudesse ter argumentos à disposição, em momento de necessidade. (ABREU, 2006:.80).

O Imperador do Brasil reclama do Ministro, sem narração direta no conto, mas desencadeia atos seguintes para o conserto de uma nomeação. A tarefa é narrada, com recursos da tautologia, mostrando uma sequência de ordens recebidas e emitidas por alguns chefes. Por analogia, os subalternos vão repetindo as ações, prestando aos seus subordinados o mesmo tratamento $\mathrm{e}$ posicionamentos que receberam dos seus superiores. Os subordinados, quando no papel de chefes reproduzem as ações sofridas. "E o diretor-geral, que era tão passivo e humilde com os superiores, quão arrogante e autoritário com os subalternos". (AZEVEDO, 2001: 294).

O argumento do ridículo sobrepõe-se ao argumento de justiça, uma vez que tratamentos idênticos para ações semelhantes são verificados no intuito de condenar pelo riso, inclusive com o uso da tautologia. A superioridade do anterior sobre o posterior, presentes em toda a narrativa reforça o argumento de ordem, assim como o argumento de qualidade, tratando do melhor sobre o pior. O chefe, que se acha superior ao chefiado, é o mesmo que acabara de ser muito humilde com o seu chefe, como os exemplos: 
a) Me considera muito e sabe que a um ministro ocupado como eu, é fácil escapar um decreto mal copiado; b) O acúmulo de serviço fez com que me escapasse tão grave lacuna; c) Havia tanto serviço... E todo tão urgente!...; d) Se o Senhor Diretor geral me não tratasse com tanto respeito e consideração! (AZEVEDO, 2001: 294).

O mesmo personagem que é cordial, gentil e humilde com seu chefe, é extremamente agressivo com seu subordinado. Os valores da mesma personagem mudam com a mudança de situação hierárquica. Sugere-se que há um consenso em que o mais elevado posto também representa que quem está acima, sempre tem razão, como vemos:

Apanhou rapidamente no ar o decreto que o ministro lhe atirou, em risco de Ihe bater na cara; - É imperdoável esta falta de cuidado!; E, dando um murro sobre a mesa, o ministro prosseguiu; 0 ministro deu-lhe as costas e encolheu os ombros, dizendo: - Bom! Mande reformar essa porcaria! E atirou-Ihe o papel, que caiu no chão; - Não me responda! Não faça a menor observação! Retire-se e mande reformar essa porcaria!; O senhor é um empregado inepto, desidioso, desmazelado, incorrigível!; - Cale-se, já lhe disse, e trate de reformar essa porcaria! (AZEVEDO, 2001: 294).

Os valores não mudam, os personagens, sim. O mais graduado não admite seu erro e a consequente incompetência. Afirma-se um ser raro e querido pelo superior, de quem goza de estima e apreço, o que Ihe dá prestígio frente ao subordinado. Prevalecem os valores hierarquizados do chefe e, na mesma proporção, dos subordinados.

O conto "O homem da cabeça de papelão", de João do Rio, escrito em 1921, narra uma história já temporalmente situada na República, cujo presidente era Epitácio Pessoa. Após significativas mudanças, com o fim da primeira Guerra Mundial, o país entra em um pequeno surto de industrialização. A classe operária cresce em número e força política, o que resulta na criação do PCB, em 1922. A 
classe média passa a reivindicar mais espaço na sociedade brasileira, exigindo eleições limpas e o fim da corrupção. Tempos que se caracterizam por crescimento industrial, greves operárias, motins militares (Revolta do Forte de Copacabana), e movimentos culturais, tais como a Semana de Arte Moderna em 1922 e exigências de reformas na educação brasileira.

O resumo do conto é o seguinte: a história se passa em um país fictício, chamado país do Sol, onde existe uma personagem, chamada Antenor, cuja cabeça "não regulava', isto é, seus atos não eram considerados normais pela sociedade "solense". Em razão disso, ele, Antenor, recebe o desprezo e a ira dos seus parentes, amigos e de muitos habitantes etc. Convencido pela sociedade de que o seu modo de agir não era correto, devido à cabeça que "não regulava", resolve consertá-la. Entra em uma relojoaria e troca a sua cabeça por uma de papelão. Com a nova cabeça, muda de comportamento, passa a falsificar, explorar, mentir e adular. Recebe a admiração de todos que antes o maldiziam. Ao receber de volta a velha cabeça, decide guardá-la por achar que a de papelão melhor combina com o seu país.

Neste conto, João do Rio envolve seu auditório nos seguintes questionamentos, enquanto expõe de maneira irônica as mazelas do "pais do Sol", que, o leitor, imediatamente, passa a correlacionar com - Brasil: O que é certo para nós tem que ser certo para os que nos cercam? Fazer o que achamos errado é certo, para conquistarmos sucesso, fama, bens materiais e admiração dos que dizem gostar de nós?

A construção da credibilidade do orador/autor se dá, inicialmente, na descrição do ambiente em que se passa a narração, os juízos de valor e seleções lexicais encaminham esta construção e alternam-se, durante o conto, com a fala de personagens secundários e do próprio protagonista. O narrador onipresente atua 
significativamente na construção do seu próprio "ethos", sendo, inclusive, capaz de criticar as ações dos personagens.

À medida que vão sendo narradas as desventuras do protagonista, o auditório, ou leitor, se identifica com ele (pathos), com a sua dor de "desajustado social". O mundo que o execra enquanto portador da cabeça original e o mundo que o idolatra, após a adoção da cabeça de papelão, são estampados aos leitores e, obviamente, objetos de crítica destes. Situações concretas de vida levam, também, o leitor a possíveis identificações vividas pelo protagonista, configurando a simpatia destes com ele.

Os argumentos atuam no convencimento do auditório, que passa a concordar com a ideia do orador. Já os lugares são fontes onde os oradores bebem, a fim de reforçar e tornar mais viva, prazerosa e persuasiva a sua tese. Trata-se de um conjunto de valores estabelecidos na sociedade, espécies de acordos coletivos, construídos culturalmente e que funcionam como "base ideológica" na formulação de argumentos, visando à adesão do auditório.

João do Rio utiliza, como Arthur Azevedo, o argumento do ridículo quase na totalidade da narrativa, descrevendo situações do cotidiano do protagonista Antenor e suas relações com figuras diversas do "país do Sol", lido como Brasil república, o que convida sobremaneira ao riso. Logo no primeiro parágrafo, o protagonista é apresentado: Antenor "não era nem deputado, nem rico, nem jornalista, portanto sem importância social", pois no país do Sol "falava-se francês com conviç̧ão, mesmo falando mal". (RIO, 1970: 196). "Antenor resolveu arranjar trabalho para os mendigos... Ficou provado que era doido". Dizia o tio de Antenor: "vagabundo é um sujeito a quem faltam três coisas: dinheiro, prestígio e posição. Desde que você não as tem, mesmo trabalhando, é vagabundo." (RIO, 1970: 198).

A importância de figurões, comerciantes, políticos e pessoas de caráter duvidoso no país do Sol, leva o autor a lançar mão do 
argumento do ridículo, no momento em que confronta as atitudes consideradas honestas de Antenor com as desonestidades dos representantes e pessoas influentes daquela sociedade.

Presente, também, em todo conto, o argumento de qualidade, tratando do melhor sobre o pior. Quando Antenor porta sua cabeça original, é sempre tido como o pior, pois não pode ser honesto e ter suas próprias idéias; ao receber a cabeça de papelão, passa, ironicamente, a ser considerado um dos melhores, senão o melhor, e convidado ao senado da república do País do Sol. A "cabeça de papelão", que pode ser lida, como cabeça vazia, destituída de valores e princípios como honestidade, ética, compromisso com a verdade etc, permite que Antenor conquiste vários pilares sociais.

Argumentos de causa e efeito para acontecimentos sucessivos, como mentir, fazer mal, trapacear, explorar, adular e falsificar e, com isso, enriquecer, ter muitos amigos, ser estimado e ver crescer a fama, também povoam a narrativa. Um dado fundamental é que os mesmos valores não são impostos a todo mundo. "Eles estão ligados à multiplicidade de grupos e de emoções. Aquele que quer persuadir deve saber previamente quais são os verdadeiros valores de seu interlocutor ou do grupo que constitui o seu auditório. (ABREU, 2006: 74).

Pontos de vista antagônicos e valores opostos permeiam todo o texto. A ironia e os recursos literários humorísticos se contrapõem a pensamentos lógicos e aparentemente racionais. No primeiro caso, vejamos alguns exemplos: "Desde menino, a sua respeitável progenitora descobriu-lhe um defeito horrível: Antenor só dizia a verdade. Não a sua verdade, a verdade útil, mas a verdade verdadeira"; (RIO, 1970: 198). "A faca serve para cortar o que é nosso para nós e o que é dos outros também para nós"; "sabendo lisonjear, é a ascensão: deputado, ministro". (RIO, 1970: 199). No segundo caso, atentamos para o parágrafo, onde o relojoeiro comenta a cabeça de Antenor: 
Senhor, na minha longa vida profissional jamais encontrei um aparelho igual, como perfeição, como acabamento, como precisão. Nenhuma cabeça regulará no mundo melhor do que a sua. É a placa sensível do tempo, das idéias, é o equilíbrio de todas as vibrações. O senhor não tem uma cabeça qualquer. Tem uma cabeça de exposição, uma cabeça de gênio, hors-concours. (RIO, 1970: 201).

O protagonista rende-se ao fato de precisar ser igual aos outros, diga-se igual à "elite política" do país do Sol, para ser aceito naquele espaço, em que a competência e a visão de futuro não são atributos válidos. A verdade é a da classe dominante, como é citado no penúltimo parágrafo: "a verdade é a dos outros". E a fina ironia das últimas palavras da obra de João do Rio: "conseguiu tudo com uma cabeça de papelão".

\section{CONCLUSÃO:}

Ensina-nos Perelman (1996: 85) que os valores universais são meios de persuasão, espécie de ferramentas espirituais totalmente separáveis da matéria que permitem moldar, anteriores ao momento de serem utilizadas e que permanecem intactas depois de serem utilizadas, disponíveis, como antes, para outras ocasiões. Essa concepção evidencia admiravelmente o papel argumentativo dos valores, ou lugares, conforme já se disse atrás.

Como diz Abreu (2006: 99), as palavras são como fios, com os quais tecemos ideias, em forma de texto. Quando usamos uma palavra, estamos fazendo uma escolha de como representar nossas ideias, nossos valores. As palavras que escolhemos têm enorme influência em nossa argumentação.

$\mathrm{Se}$, na antiguidade, o orador precisava dispor de certas técnicas oratórias para convencer os ouvintes ou cidadãos presentes nas assembleias da ágora grega, artistas da palavra, como Arthur Azevedo e João do Rio, não têm tarefa menos "engenhosa". Expor, a 
partir do expediente da ironia, as feridas do Brasil e suas contradições históricas exige maestria no trato com as palavras.

A habilidade de analisar uma situação sob diferentes pontos de vista, é importante em qualquer área, pois está ligada ao exercício da criatividade e, obviamente, da argumentação. Valores como o verdadeiro, o bem, o justo, o absoluto, o certo, o normal dependem do que é aceito em uma determinada sociedade, ou em uma determinada época, ou cultura. O modo como a sociedade "solense" julgava Antenor demonstra o que se está querendo dizer. Os valores considerados aceitos por tal sociedade são risíveis quando defrontados com a "honestidade" anterior de Antenor, que acabou "capitulando" diante da pressão social.

No conto de Arthur Azevedo, o mesmo personagem que é terno, cortês e humilde com seu chefe, é extremamente hostil com seu subalterno. Os valores da personagem mudam de acordo com a variação hierárquica. O que provoca o riso no leitor é o fato da pessoa de posto mais elevado sempre ter razão, mesmo sendo um comprovado incompetente.

\section{REFERÊNCIAS :}

AZEVEDO, Arthur. De cima para baixo. In COSTA, Fábio Moreira da. Os 100 melhores contos de humor da literatura universal. Rio de Janeiro: Ediouro, 2001, pp. 293-95.

ABREU, Antônio Suarez. A arte de argumentar - Gerenciando Razão e Emoção. São Paulo: Ateliê Editorial, 2006

ARISTÓTELES. Arte poética e arte retórica. Rio de Janeiro: Ediouro, 1969.

BAKHTIN, M.M. A cultura popular na Idade Média e no Renascimento: 0 contexto de François Rabelais. DF, Universidade de Brasília, 1993.

GOTLIB, Nádia Battella. Teoria do conto. São Paulo: Ática, 2000.

PERELMAN, Chaïm. Tratado da argumentação. São Paulo: Martins Fontes, 2002; 
REBOUL, Olivier. Introdução à retórica. 2. ed. São Paulo: Martins Fontes, 2004.

RIO, João do. O homem da cabeça de papelão. In: MAGLHÃES JUNIOR. R. Antologia de Humorismo e Sátira. Rio de Janeiro: Civilização Brasileira, 1970, pp. 196-201. 